\title{
Sistem Informasi Penjualan Barang pada Toko Candra Berbasis Android
}

\author{
Hartati Dyah Wahyuningsih*1, Paryanta $^{2}$, Hetri Candra Winoto ${ }^{3}$ \\ ${ }^{1,3}$ Program Studi Sistem Informasi, STMIK AUB, Surakarta, Indonesia \\ ${ }^{2}$ Program Studi Teknik Komputer, STMIK AUB, Surakarta, Indonesia \\ e-mail: *1 hartati.dyah@stmik-aub.ac.id, ${ }^{2}$ paryanta@stmik-aub.ac.id, ${ }^{3}$ hetric@gmail.com
}

\begin{abstract}
Abstrak
Toko Candra adalah suatu badan usaha yang bergerak di bidang penjualan barang kebutuhan pokok sehari-hari. Seluruh kegiatan operasioanl dilakukan secara manual bahkan owner sampe kesulitan membuat rekap laporan penjualan karena tidak adanya data yang tersimpan. Untuk membantu proses transaksi penjualan di Toko Candra maka perlu dibuatkan Sistem Informasi Penjualan Barang berbasis Android. Selain digunakan sebagai kasir namun juga dapat melakukan pemesanan barang secara online. Hasil perancangan sistem informasi penjualan ini menggunakan metode pengembangan sistem waterfall. Untuk analisa kelemahan sistem menggunakan analisa PIECES, sedangkan untuk menggambarkan alur data menggunakan flowchart sistem dan Unified Modeling Laguange. Bahasa pemrograman yang digunakan adalah Android Studio. Berdasarkan pengujian yang telah dilakukan menggunakan blackbox testing, sistem yang dibangun dapat membantu masalah yang dihadapi Toko Candra.
\end{abstract}

Kata kunci: Toko Candra, Sistem Informasi Penjualan, Android

\section{PENDAHULUAN}

Sistem informasi sangat dibutuhkan dalam suatu organisasi baik instansi pemerintah, instansi swasta maupun lembaga-lembaga sosial sebagai yang dapat mempermudah dalam proses memberikan informasi terutama dalam proses pengolahan data dan pembuatan laporan. Pemanfaatan tekhnologi smartphone Android juga dapat mempermudah dalam mencari informasi yang diinginkan dan sebagai alat komunikasi tanpa mengenal jarak dan waktu.

Perkembangan terakhir sistem informasi penjualan kini sudah mulai dikembangkan pada perangkat mobile berbasis Android. Android merupakan sistem operasi berbasis linux yang memang diperuntukan bagi smartphone maupun komputer tablet. Hal ini cukup beralasan mengingat terdapat segudang kelebihan yang dimiliki aplikasi berbasis Android dengan sistem informasi administrasi berbasis Android, pengguna aplikasi dapat menggali informasi dimana saja dan kapan saja.

Toko Candra didirikan oleh pasangan suami istri Karimin dan Suharti pada tahun 2000 berlokasi di Jumapolo Rt 03/01 Jumapolo Karanganyar, muncul ide untuk merubah rumah menjadi Toko Kelontong dengan bermodalkan uang pinjaman dari bank mereka membangun Toko Candra. Awal berdiri pelanggan yang beli di Toko Candra hanya sekitar daerah Jumapolo namun setelah terjadinya perkembangan dan peningkatan penjualan, pelanggan bertambah banyak dan terus meningkat setiap hari sampai mencapai 100 pelanggan tetap sampai saat ini. Omset yang didapat saat awal Toko Candra didirikan yaitu hanya Rp.200.000 per bulan namun setelah peningkatan dari tahun ke tahun sampai sekarang omset yang didapat mampu mencapai Rp.50.000.000 per bulan. 
Toko Candra adalah suatu badan usaha yang bergerak di bidang penjualan barang retail seperti rokok, sabun mandi, sikat gigi, mie instan, minuman botol, minyak goreng, gula, dan lain-lain. Barang-barang yang dijual adalah kebutuhan sehari-hari, namun di Toko Candra masih menggunakan sistem penjualan manual yaitu pelanggan mengambil barang-barang, kemudian diserahkan ke kasir setelah itu kasir mencatat barang tersebut ke nota dan mentotal harga barang agar dibayar oleh pelanggan, dan dalam hal laporan pun belum sesuai dengan sistem penjualan yang ada.

Berdasarkan permasalahan yang ada maka peneliti tertarik untuk membangun aplikasi, yang dapat digunakan untuk mempermudah proses pelayanan, transaksi pembelian, laporan keuangan dan pesan antar bagi pelanggan dalam lingkup sekitar area Toko Candra, untuk itulah peneliti memilih judul "SISTEM INFORMASI PENJUALAN BARANG PADA TOKO CANDRA BERBASIS ANDROID”.

\section{METODE PENELITIAN}

\subsection{Analisa Sistem}

Untuk menganalisa kelemahan sistem diperlukan langkah untuk mengidentifikasi dan memberikan solusi terhadap kelemahan sistem yang ada, maka sebagai landasan penulis menggunakan metode atau kerangka PIECES yang terdiri dari performance, information, economy, control, efficiency dan service. Analisis ini digunakan sebagai alat ukur untuk menentukan sistem baru layak atau tidak karena enam aspek ini harus mengalami peningkatan ukuran yang lebih baik dari sistem lama agar dapat mendukung dalam kelancaran proses admin.

Tabel 1. Tabel Analisis Kelemahan Sistem

\begin{tabular}{|l|l|}
\hline \multicolumn{1}{|c|}{ Analisa } & \multicolumn{1}{|c|}{ Yang sedang berjalan } \\
\hline $\begin{array}{l}\text { Perfomance } \\
\text { (Kinerja) }\end{array}$ & $\begin{array}{l}\text { Pengolahan data masih dilakukan secara manual tanpa bantuan sistem } \\
\text { sehingga membutuhkan banyak waktu dan sering terjadi kesalahan } \\
\text { ketika mencata data-data. }\end{array}$ \\
\hline $\begin{array}{l}\text { Information } \\
\text { (Informasi) }\end{array}$ & $\begin{array}{l}\text { Informasi mengenai stok barang dan laporan stok barang serta laporan } \\
\text { penjualan disimpan dalam buku sehingga mengurangi keakuratan dari } \\
\text { informasi tersebut. }\end{array}$ \\
\hline $\begin{array}{l}\text { Economy } \\
\text { (Ekonomi) }\end{array}$ & $\begin{array}{l}\text { Biaya yang dikeluarkan relative tinggi karena harus membeli buku } \\
\text { untuk stok barang, laporan penjualan }\end{array}$ \\
\hline $\begin{array}{l}\text { Control } \\
\text { (Keamanan) }\end{array}$ & $\begin{array}{l}\text { Keamanan data-data sangat kurang, karena data hanya disimpan } \\
\text { didalam buku tentu saja rentan dengan hilang atau rusak karena sifat } \\
\text { kertas yang mudah rusak. }\end{array}$ \\
\hline $\begin{array}{l}\text { Efficiency } \\
\text { (Efisiensi) }\end{array}$ & $\begin{array}{l}\text { Dalam pengerjaan data penjualan dan laporan penjualan dicatat kedalam } \\
\text { buku sehingga membutuhkan waktu yang lama dan tidak efektif. }\end{array}$ \\
\hline $\begin{array}{l}\text { Service } \\
\text { (Layanan) }\end{array}$ & $\begin{array}{l}\text { Belum memberikan kemudahan dalam pengerjaan pendataan barang dan } \\
\text { laporan penjualan barang. }\end{array}$ \\
\hline
\end{tabular}

\subsection{Perancangan Sistem}

Perancangan sistem adalah merancang atau mendesain suatu sistem yang baik, yang isinya adalah langkah-langkah operasi dalam proses pengolahan data dan prosedur untuk mendukung operasi sistem. Perancangan sistem juga mencakup evaluasi efektivitas dab efisiensi relatif atas pilihan-pilihan rancang bangun sistem yang dipandang dari kebutuhan keseluruhan. Perancangan sistem atau proses menspesifikasikan rincian solusi yang dipilih oleh proses analisis sistem.

Tabel 2. Flowchart Sistem Yang Dibangun 


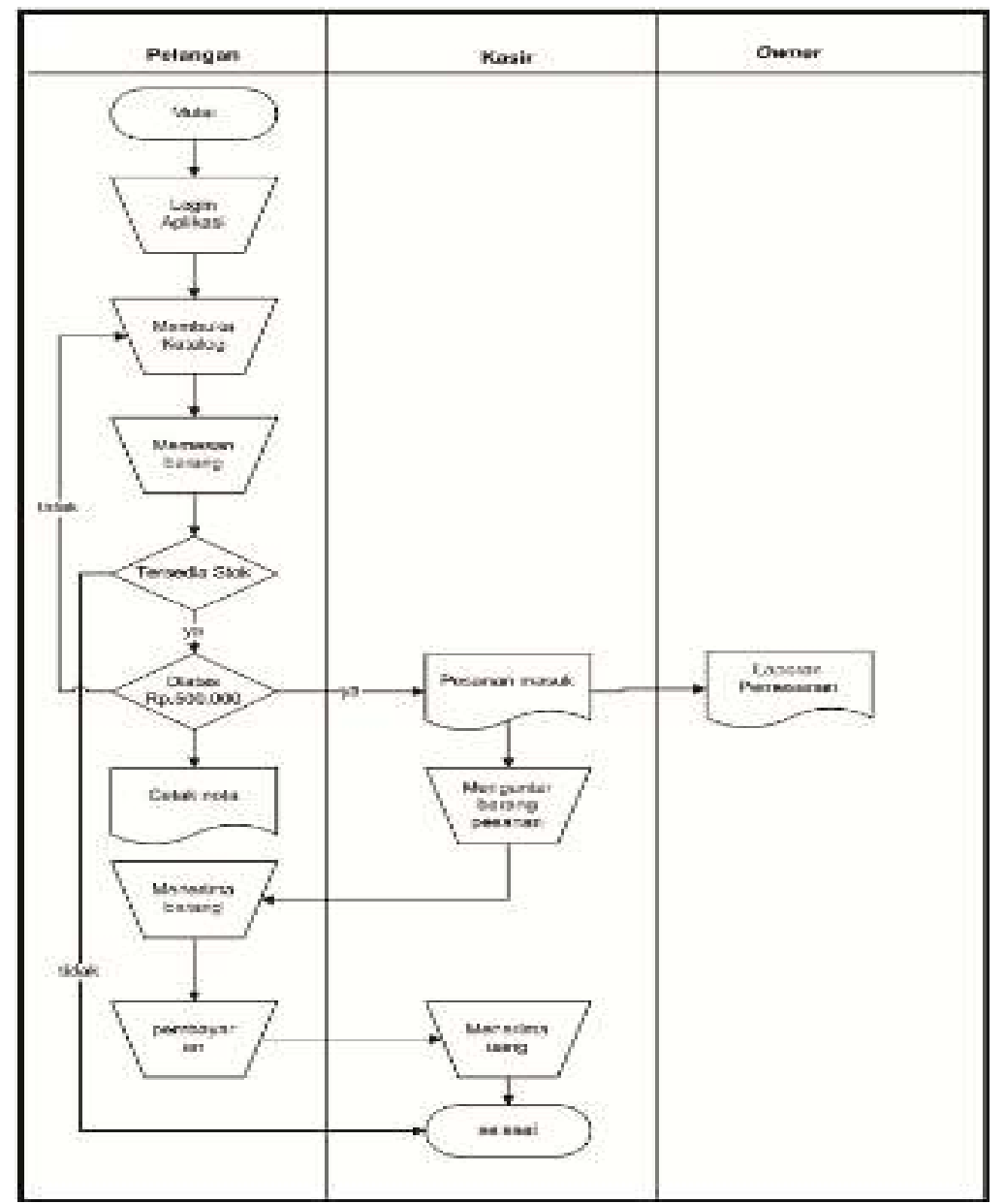

Tabel 3 Flowchart transaksi penjualan di Toko Candra yang dibangun 


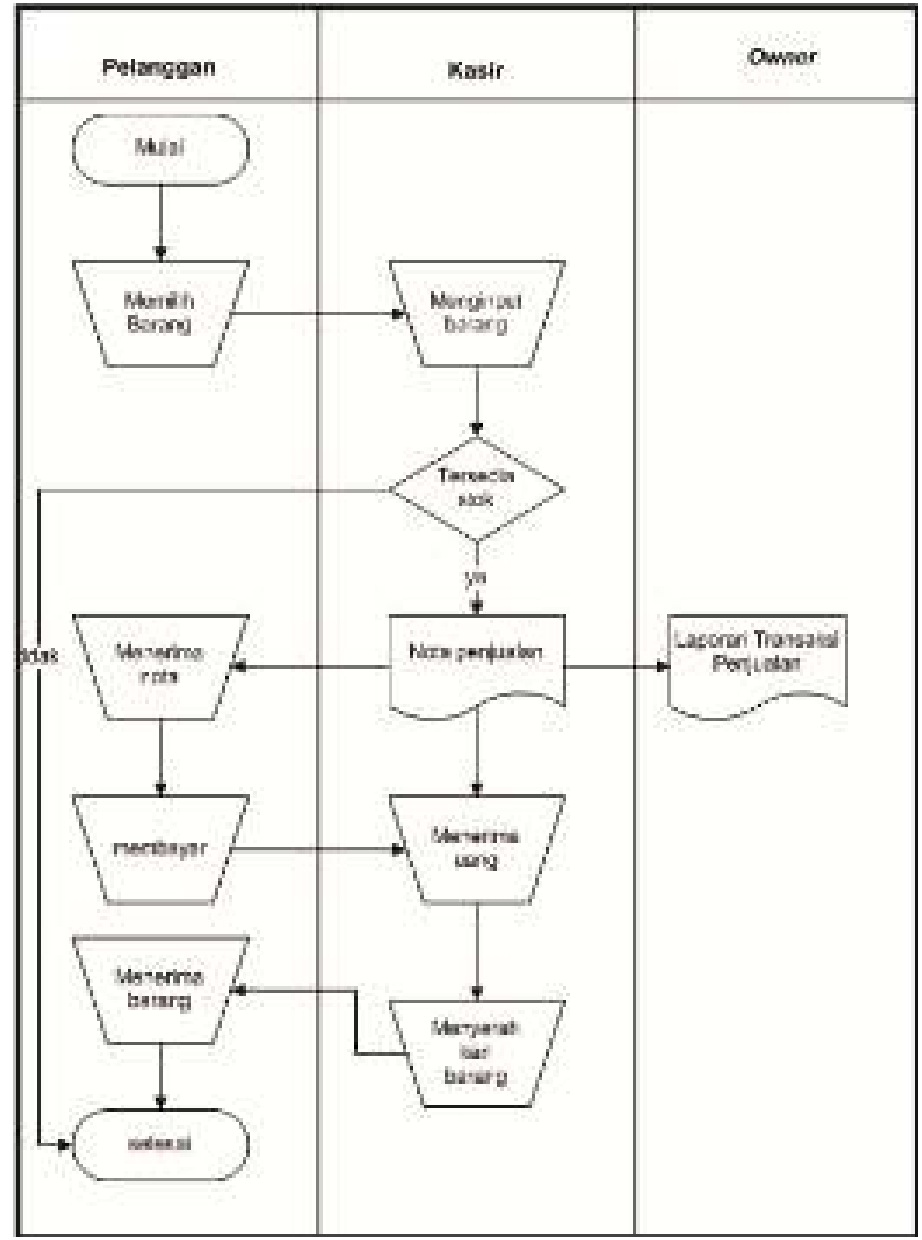

\section{HASIL DAN PEMBAHASAN}

Dalam pembuatan aplikasi ini dibutuhkan suatu pembahasan untuk menguraikan program dan analisis dari hasil program yang telah dibuat. Tujuan pembahasan ini adalah untuk mengetahui apakah program yang dibuat sudah bekerja seperti yang diharapkan atau belum. Berikut adalah proses pembahasan interface atau antarmuka program:

3.1. Halaman Owner

1. Halaman Login Admin

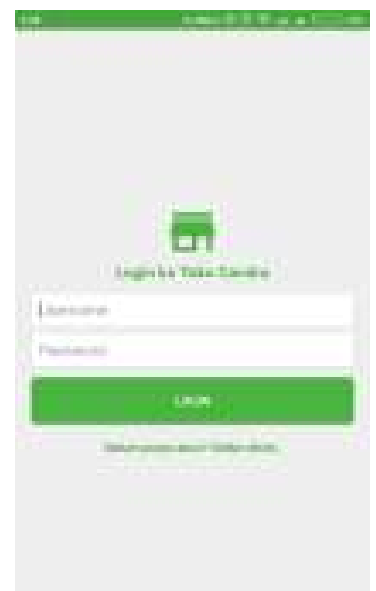

Gambar 1 Halaman Login Admin 
Halaman login admin, digunakan oleh owner untuk masuk kedalam aplikasi dan mengelola data karyawan dan melihat laporan transaksi, laporan pembelian dan laporan pemesanan.

2. Halaman Utama

3. Halaman Menu Laporan

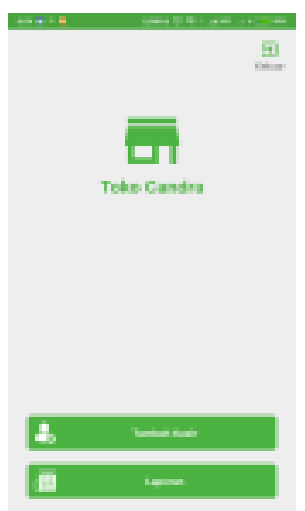

Gambar 2 Halaman utama

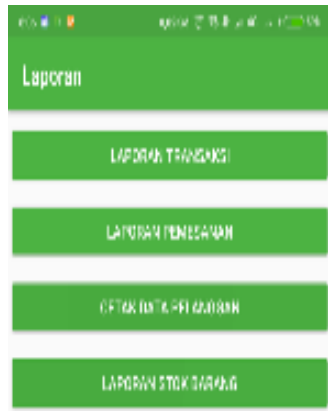

Gambar 3 Halaman Menu Laporan

Halaman menu laporan, menampilkan laporan yang diolah yaitu laporan transaksi, laporan pemesanan, laporan data pelanggan, dan laporan stok barang.

3.2. Halaman Karyawan

1. Halaman Utama Karyawan

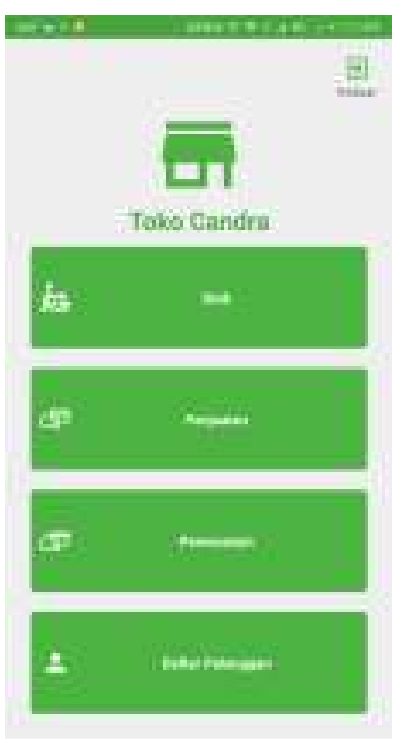

Gambar 4 Halaman utama karyawan

Halaman utama karyawan, menampilkan menu pembelian, penjualan dan laporan. Menu stok digunakan untuk menambah data barang masuk, menu penjualan digunakan untuk melakukan 
transaksi penjualan secara offline, menu pemesanan digunakan untuk melakukan transaksi pemesanan dari pelanggan secara online, menu daftar pelanggan digunakan untuk menampilkan data pelanggan yang sudah terdaftar dalam aplikasi.

2. Halaman List Barang

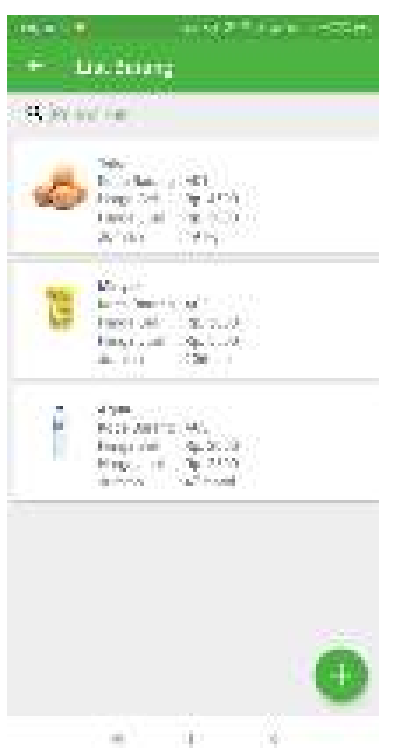

Gambar 5 Halaman list barang

3. Halaman List Penjualan Barang

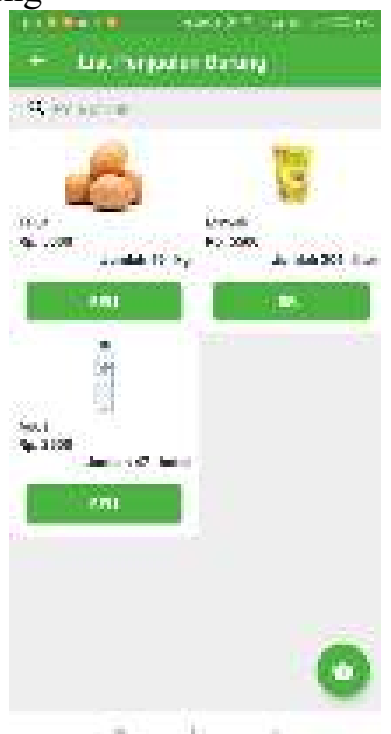

Gambar 6 Halaman list penjualan barang

4. Halaman Daftar Pelanggan

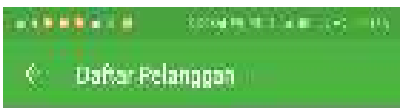

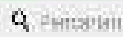

finmavi Wisolyn:

srantses

Tulor W dod:

arwetriks

Gambar 7 Halaman daftar pelanggan

GO INFOTECH: JURNAL ILMIAH STMIK AUB Vol. 25, No. 1, Juni 2019 : 11 - 17 


\section{KESIMPULAN}

Hasil perancangan penelitian ini menggunakan Flowchart, UML (Unified Modeling Language) yang tediri dari Usecase Diagram, Activity Diagram, Sequence Diagram, Class Diagram, dan Entity Relationship Diagram. Sedangkan untuk metode pengembangan sistem menggunakan Metode Waterfall. Pengembangan sistem menggunakan Bahasa pemrograman pendukung. Hasil perancangan Sistem Informasi Penjualan Barang Pada Toko Candra menggunakan metode pengembangan sistem waterfall. Untuk perancangan proses terdiri dari flowchart, usecase diagram, activity diagram, sequence diagram, class diagram dan relasi antar tabel. Perancangan Sistem Informasi Penjualan Barang Pada Toko Candra menggunakan Bahasa pemrograman Android Studio. Sedangkan untuk pengolahan database menggunakan MySQL. Sistem Informasi Penjualan Barang Pada Toko Candra, digunakan sebagai media untuk mengolah data karyawan, data barang, melakukan pemesanan barang secara online dan dapat melakukan transaksi penjualan berbasis android. Sistem Informasi Penjualan Barang Pada Toko Candra, dilengkapi dengan pengolahan laporan transaksi, laporan pembelian dan laporan pemesanan barang yang dikelola oleh admin kemudian diteruskan kepada owner. Aplikasi Penjualan Toko Candra berbasis Android, telah diimplementasikan pada Toko Candra dan mampu meningkatkan pelayanan, kemudahan bertransaksi dan menghemat wakt pelanggan.

\section{SARAN}

Sistem Informasi Penjualan Barang pada Toko Candra, masih dapat dikembangkan lagi sebagai studi skripsi, yaitu dengan menambahkan fasilitas pembayaran dengan sistem saldo atau E-money. Bagi pelanggan yang tidak memiliki uang tunai dapat mengisi saldo guna dapat bertransaksi dengan aplikasi ini.

\section{DAFTAR PUSTAKA}

[1] Henry. 2000. Akuntansi Basis Pengambilan Keputusan Bisnis. Jakarta: PT Gramedia Pustaka Utama.

[2] Herawati, Prabowo Pudjo Widodo. 2001. Menggunakan UML. Jakarta: Informatika.

[3] Jeffrey. L. Whitten, Lonnie D.Bentley, Kevin C. 2001. System Analysis and Design Methods 5thEd. McGraw-Hill.

[4] Jogiyanto. 2005. Analisis \& Desain Sistem Informasi: Pendekatan Terstruktur Teori dan Praktek Aplikasi Bisnis. Yogyakarta: Andi.

[5] Kristanto. 2003. Konsep dan Perancangan Basis Data. Yogyakarta: Andi.

[6] Kuncoro, David Wahyu. 2015. Sistem Kasir Dan Pendataan Stok Barang Pada Tata Distro Pacitan. Jurnal: Bina Sarana Informatika Surakarta.

[7] Ladjamudin, Albahra. 2005. Analisis dan Desain Sistem Informasi. Yogyakarta: Graha Ilmu.

[8] Pressman, Roger S. 2001.Rekayasa Perangkat Lunak Pendekatan Praktisi. Yogyakarta: Andi.

[9] Permatasari, Angelina. 2015. Rancangan Sistem Penjualan Pada Toko Kue. Jurnal: Bina Nusantara Surakarta.

[10] Rahman, M. Fatkhur. 2016. Analisa Dan Perancangan Sistem Kaasir Menggunakan Model Prototype. Jurnal: Universitas Nusantara PGRI Kediri.

[11] Safaat, Nazruddin. 2012. AndroidPemrograman Aplikasi Mobile Smartphone dan Tablet PC Berbasis Android . Bandung: Informatika Bandung.

[12] Sandi. 2012. Definisi Pengertian dan Fungsi XAMPP Lengkap. https://indoskripsi.com diakses pada 22 November 2017.

[13] Shalahuddin, M dan Rosa. 2015. Rekayasa Perangkat Lunak Tersruktur dan Berorientasi Objek. Bandung : Informatika.

[14] Sutabri, Tata. 2005. Sistem Informasi Manajemen. Yogyakarta: Andi Offset. 